como ejemplo característico de ese titubeo: el ductus es uno en las líneas 3 y 5 , otro en la 1 , otro en la 12 y otro en la 10 . Vacilación propia de quien escribe con letra que no es la suya, y sin tener delante modelo del cual copiar.

La firma, trazada al hilo de otra, tiene un carácter muy diferente del resto de la plana, pero falta en ella el rasgueo seguro y limpio de Cervantes, sobre todo en la rúbrica, donde se ha sustituido con un tosco barullo el cruzadillo nervioso del original.

No vale la pena buscar más argumentos, porque es tan evidente la falsificación, que basta poner al lado cualquier autógrafo cervantino para que la conmovedora carta se hunda.

Sánchez Cantón, escribiendo sobre la supuesta Memoria de Velázquez que guarda la Real Academia Española como obsequio de don Adolfo de Castro, decía hace años: "es de desear que la Academia coloque en una vitrina el ejemplar de la Memoria acompañado del retrato de Cervantes" 32 . A tan atractiva exposición podría unirse la emocionante carta que escribió en el siglo xIx cualquiera, menos el insigne autor del Quijote 33 .

Madrid, 14 de marzo de 1962 .

ANTONio RoDríguez-MoÑino

\title{
GANIVET EN LAS HUELLAS DE GALDÓS Y ALARCÓN
}

Existe, sin duda, una gran diferencia entre la génesis de La conquista del reino de Maya por el íltimo conquistador español Pio Cid y la de Los trabajos del infatigable creador Pio Cid. La primera de estas obras se inscribe perfectamente en el ambiente "africano" de la Bruselas colonialista de fines de siglo: Ganivet da a su novela una significación europea, si bien la pone también bajo la influencia de problemas españoles de orden interno y de relaciones exteriores como los de la política africana del país (Ia cual había proporcionado ciertas ventajas a España en el tratado hispano-marroquí de 1860, y luego en la Convención internacional de Madrid de 1880 ). La segunda novela se refiere al período propiamente español de Gavinet y tiende a ser bajo varios aspectos una novela ejemplar que toma como principal doctrina ciertos temas del Idearium español. En ella, Gavinet cree ser Pío Cid y muestra personajes más cercanos a nuestra sensibilidad, y que reciben el aporte de las ideas liberales de la época. Sin embargo, también se puede descubrir en el Pío Cid de La conquista del reino de Maya al hombre de cultura europea que choca con una civilización extraña cuyas instituciones acaba por aceptar, de manera que éstas lo marcan definitivamente. (Cuando Pío Cid vuelve a España, de retorno de su

32 F. J. SÁnchez Cantón, La libreria de Velázquez, Madrid, 1925; véase la p. 1, nota primera.

${ }^{33}$ Addenda.-Como muestras de veneración por el "preciosísimo autógrafo" (con mención del "sitio de honor" que ocupa en la Real Academia), cf. E. Cotarelo, Efemérides cervantinas, Madrid, 1905, p. 272, y Marqués dE Pidal, "Últimos años de Cervantes", en Cervantes y el "Quijote", Madrid, 1905. pp. 75-80. 
proeza en el continente negro, el ambiente de Madrid le resulta bastante incómodo, y apetece la semianarquía de las costumbres africanas).

La atmósfera de Maya es utópica, lo cual le ofrece a Ganivet ancho campo para exponer sus teorías sociales. Algunas de estas ideas tenían precedentes en Pedro Antonio de Alarcón y en Pérez Galdós, según trataré de mostrar en las páginas que siguen.

Ganivet es un lector atento de Galdós, de quien habla varias veces en su epistolario ${ }^{1}$. Don Benito -dice en la Carta $\mathbf{x x}$ - logra en sus novelas una gran unidad que parece realizada de un solo golpe; no importa que a veces se descuide: esto mismo revela "la maestría suprema del que ya no necesita fijarse para encontrar la forma perfecta" (p. 966). En la Carta v, después de hablar del loco en la literatura, y de decir a propósito de Swift y Heine que "cuando el autor es subjetivo, el loco que asoma la cabeza es él mismo", mientras que "cuando es objetivo, los locos son los personajes", pero el resultado es idéntico, añade (p. 859):

No niego que haya exposición en hacer afirmaciones absolutas, y creo también que como la realidad tiene muchas caras, cuando se toma un punto de vista sistemáticamaente todo se deja ver por este punto, $y$, por consecuencia, todas las obras artísticas serian jaulas de locos. En Galdós, por ejemplo, sacaríamos bastantes; los mejores, Orozco, Viera, Guillermina, Leré, el padre de las "Miau", etcétera. Pero lo sustancioso en esta cuestión es que el punto de vista ofrece un criterio fijo para crear tipos con probabilidad de acierto, y por otro lado la observación se facilita, circunscribiéndose a los rasgos ridículos y a las locuras humanas, puesto que su combinación parece ser que da una idea completa y perfecta de lo que somos.

Este juicio sobre Galdós arroja no poca luz sobre la intención del propio Ganivet en La conquista del reino de Maya; su tendencia a poner de relieve lo ridículo de ciertas instituciones de este reino se convierte en un instrumento de sátira social.

Ganivet ataca, por ejemplo -al igual que Galdós en algunos pasajes de Angel Guerra- la institución del matrimonio; ve en este sacramento "una de las últimas bajezas que puede cometer el hombre por someterse al brutal instinto de la especie, al crescite et multiplicamini". Según él, la monogamia es rara en "los pueblos que obran con algún sentido de la Naturaleza"; existe "el comunismo absoluto" en los pueblos pequeños que forman unidad política. La poligamia, en cambio, aparece en las sociedades fuertes y ricas, donde los hombres pueden capturar o comprar mujeres. La poliandria es frecuente en los pueblos agrícolas: sus hombres, débiles en la guerra, deben compartir entre sí los favores de las mujeres que no han sido capturadas por pueblos enemigos en "razzias" bélicas. Ganivet nota que tanto la poligamia como la poliandria son superiores a la monogamia (Carta IV, pp. 852-853). Ésta representa, para él, un sistema de vida esencialmente católico. La monogamia concede a la mujer una importancia social mayor que la polian-

${ }^{1}$ Cito a Ganivet por la edición de Obras completas, Madrid (Aguilar), 1943; La conquista del reino de Maya está en el tomo 1; Los trabajos de Plo Cid y el epistola. rio, en el tomo 2. 
dria o la poligamia, pues habiendo una mujer para cada hombre, se equilibra el papel femenino con el masculino. Al preferir los otros dos sistemas, Ganivet, sin caer propiamente en la misoginia, relega a la mujer a un segundo plano. En la sociedad de Maya, el delito más grave en una mujer es la fealdad; después vienen defectos como la holgazanería, la esterilidad, el adulterio (La conquista..., p. 424). Las mujeres llevan una vida muy retirada en gineceos, costumbre ciertamente loable, puesto que necesitan permanecer en el hogar para cumplir con los deberes domésticos y "tratarse con otras personas de su sexo y de su clase". Entre los europeos, este problema casi nunca se resuelve armónicamente: las mujeres viven recluidas en una situación miserable, o acaban por abandonar el hogar (ibid., p. 305).

Galdós, por su parte, ve con bastante simpatía las relaciones no consagradas por la religión. En Fortunata y Jacinta hay un conflicto entre el sistema legitimado por Dios y las relaciones ilegales y a-religiosas; entre Jacinta ("la mona del cielo") y Fortunata, la mujer del pueblo pronta a dar su vida por el hombre amado. Galdós sale a la defensa de los amantes situados al margen de la moral religiosa, y si hace simpático al personaje de Fortunata es para revestirlo de una mayor humanidad ante los ojos de los lectores españoles de fines del siglo. Jacinta posee cualidades innegables, pero Fortunata se presenta con un credo tan sólido como el de su antagonista. Al final, Jacinta muestra su gran generosidad al adoptar al hijo natural de Fortunata y de su esposo, lo cual equivale a legitimar el fruto de un amor que Galdós nunca condena.

Pero en Ángel Guerra, Galdós precisa aún más su punto de vista sobre las relaciones conyugales y extra-conyugales. Recordemos un pasaje famoso ${ }^{2}$ :

[Don PrTo]-El querer no es pecado, siempre que no haya perjuicio de tercero, y si pusieron en la tabla aquel articulito fue por razones que tendria el señor de Moisés allá, en aquellos tiempos atrasados. Pero no me digan a mi que por querer se condena nadie.

[ÁNgel Guerra]-Presentada la cuestión así, yo también sostengo lo mismo. Por amor nadie se condena; al contrario...

[Don PrTo]-Ni se peca, hombre, ni se peca en nada de lo que al amor toca... ¿Que tienes un retozo con mujer libre? Pues no faltas, no faltas, y asunto concluido... (p. 19).

Y Don Pito continúa diciendo que todo lo existente en la naturaleza pertenece a Dios; si Angel Guerra quiere fundar un convento, que lo funde, pero regido por reglas religiosas diferentes, que permitan aumentar la especie y perfeccionarla. La castidad, ¿para qué observarla? En lugar de consumirse, ¿por qué no multiplicar el número de niños? $Y$ Don Pito se explaya acerca de las excelencias de la secta de los mormones, que permiten la poligamia, y entre los cuales jamás riñen las mujeres, aunque a veces haya hasta veinticinco en una casa. "Sí, hombre, decídete, y déjate de simplezas. Pero si lo enamorado no quita lo religioso..." (p. 24).

Esta libertad en los lazos sentimentales abarca incluso el amanceba-

2 Angel Guerra, ed. de Madrid, 1891 ; todas las citas se refieren al tomo 3. 
miento. Casiano, por ejemplo, considera a Dulcenombre como la esposa de Ángel, aunque no estén casados: "Pero no seamos materiales. Todo se reduce a que no hubo bendiciones. Suponte ahora tú que yo no hubiera estado casado con mi difunta, y que mi difunta, en vez de fallecer de calenturas, se hubiera metido a monja. ¿Pues dejaría yo de ser en tal caso tan viudo como ahora lo soy?" (p. 145).

Es notable el paralelismo entre estas frases y la condición en que Ganivet coloca el matrimonio, la monogamia y los hijos naturales en $L a$ conquista del reino de Maya. Pocas veces trató Galdós con tanta franqueza y desenfado el problema del amor libre, y pocas veces estuvo tan cerca del pensamiento de Ganivet. Pío Cid llega a un país utópico en que, por milagro, se cumplen sus deseos de una vida libre, sin obstáculos. Encuentra cómodo el sistema de la poligamia y de la unión libre al suplantar en su oficio marital al juez supremo de Maya. Las mujeres del juez, adoptadas por Pío Cid, le revelan a éste el código del amor maya; los hijos nacidos de una verdadera unión sentimental no sancionada por el casamiento son más respetados que los frutos del matrimonio, porque son, indudablemente, el fruto del amor.

Cuando lee Ángel Guerra, Ganivet ya está destruido por el conflicto sentimental que tanto habrá de influir en su suicidio. De su amor por Amelia Roldán nació un hijo, y la situación de los amantes se hizo intolerable, tanto por la conducta de la propia Amelia como por la actitud de la familia de Ganivet, que condenó siempre esos lazos ilegales. Entre el cúmulo de influencias que se ejercen sobre el escritor entre los años 1888 y 1898 (su período de formación y de actividad), fuerza es reconocer que esa pasión fue uno de los elementos generadores que hicieron de Ganivet un escritor de tendencias sociales avanzadas. En la época que vivió en Amberes (años en que sus facultades mentales no estaban aún en peligro), debió de interrogarse a menudo acerca de su situación exacta frente a la sociedad. Desde este punto de vista, La conquista del reino de Maya revela ciertos deseos utópicos que fueron evidentemente reforzados por la lucha que contra ciertos tabús sociales trababa en España una minoría deseosa de abrir nuevos horizontes al país. Gracias a la oportunidad de viajar al extranjero, Ganivet sintió con mayor plenitud los aspectos que estorbaban el progreso social de España, y desarrolló en su libro esos temas, que nada tenían de chocante en un ambiente como el de Bélgica o el de Francia.

Evidentemente, es difícil conjugar un absolutismo monárquico como el de La conquista del reino de Maya con una casi anarquía en las costumbres; pero ésta es una de las características de Ganivet. Tiene dos puntos de vista, bastante diferentes: uno, exento de todo subjetivismo, cubre a toda la sociedad española; otro, personal, sólo tiene en cuenta su propia vida. Si tomamos como base de la afinidad entre Galdós y Ganivet el vacío enorme que el primero iba a llenar en la vida del segundo al sancionar un estado civil anómalo, nos daremos cuenta más fácilmente de la línea social seguida en La conquista del reino de Maya.

Robert Ricard ha destacado ya $\left(B H i, 60,195^{8}\right.$, p. $\left.4^{8} 4\right)$ ciertas afinidades y oposiciones entre Pío Cid y Agustín Caballero, el protagonista de Tormento. Pero al lado de esta nueva influencia galdosiana hay que 
poner otra, bastante inesperada: la influencia de Pedro Antonio de Alarcón. Ganivet tenía en gran estima al autor de El sombrero de tres picos. "Si lo leyeras después de conocer el terreno -escribía a Navarro Ledesma (Carta xxvir,, p. 1017)-, le pondrías muy por encima de Pereda y a la altura de Pérez Galdós". Uno de los libros de Alarcón, La Alpujarra, contiene una verdadera apología de los moros, y otro, la Historia de mis libros, ataca la política árabe de España al criticar el papel de Felipe II y el de la Inquisición. Alarcón es partidario de una actitud más humana, como la de Isabel la Católica y Carlos V, una actitud que hubiera impedido ahogar en España la cultura musulmana. Es fácil enlazar este punto de vista con el de Ganivet, que en La conquista del reino de Maya demuestra su desprecio por la política colonizadora de Leopoldo II de Bélgica y por el mal uso de la palabra "civilización". Ambos escritores unen sus voces para que se reconozca cierta autonomía a los naturales del Mahgreb y a los del África ecuatorial. En varios momentos, Ganivet vincula el destino de los musulmanes con el del gobierno español, y llega a hacerse eco del sueño utópico de los árabes de volver a imperar en España.

Sin embargo, la huella de Alarcón es más visible aún en Los trabajos de Pio Cid. Alarcón presentaba en El escándalo dos personajes opuestos, Lázaro y Fabio Conde. Lázaro posee su fuerza independientemente de la religión, y si es cierto que su postura coincide con la del jesuita Pedro Alonso, no invoca, como éste, el nombre de Dios para sus acciones. Es, así, una especie de Agustín Caballero extra-terrestre, y se acerca muchísimo al Pío Cid de la segunda novela de Ganivet. El lado profético de Pío Cid, esa intuición tan aguda que le permite adivinar casi los pensamientos, ese desdén por todo provecho material que es ahora una de sus características fundamentales, le hacen perder mucha fuerza como personaje de novela, haciéndosela ganar en cuanto símbolo. Es ése justamente el efecto buscado por Alarcón en El escándalo

Galdós, más humano, mejor observador, más realista, en fin, construye un personaje más fácil de asimilar. No obstante, Agustín Caballero anuncia ya a Pío Cid. Agustín Caballero llega a España (lo mismo que Lázaro) después de una prolongada permanencia en América. Vive allí con las facilidades que da una pingüe fortuna. Lázaro decide regresar a Europa perseguido y trastornado por la calumnia. En ambos personajes se opera una exacerbación de sus características temperamentales; ambos se vuelven misántropos, luego de haber llevado a cabo una verdadera odisea lejos de la patria. Pío Cid vuelve a España aureolado por una fama de "conquistador" que hace desbordar la imaginación de quienes lo rodean, pero la realidad de su pasado permanece desconocida aun para los más allegados a él. Galdós presenta a Agustín Caballero como un héroe que ha prestado grandes servicios a la civilización americana, y que se siente desorientado por el cambio de atmósfera en una ciudad como Madrid, donde la gloria consiste en saber hacer bien el nudo de la corbata (p. 39) ${ }^{4}$. Agustín Caballero es un hombre tímido, rico, ordena-

${ }^{3}$ En la Carta XIV (p. 938), Ganivet hace algunas reflexiones acerca de esta novela y acerca de su personaje Lázaro.

* Cito Tormento por la edición de Madrid, 1906 . 
do; amigo de las comodidades, ha descuidado por completo la cultura enciclopédica. Pío Cid es exactamente lo contrario. Pero estos rasgos opuestos se encuentran en ciertos momentos y producen resultados parecidos. Por ejemplo, el personaje de Galdós había vivido quince años sin mirarse en un espejo, sin reparar en su apariencia física, y solía quedarse serio y taciturno en medio de la alegría general, incapaz de sostener una conversación sobre temas superficiales (pp. 40-41). Evidentemente, estos rasgos podrían convenir muy bien al personaje de Ganivet. Pero, a pesar de su timidez, Agustín Caballero se burla de la sociedad cuando está en juego su felicidad personal. Cuando Amparo trata de matarse a causa de sus relaciones con Pedro Polo, Agustín va al encuentro de su novia y se la lleva, ante los ojos asombrados de Bringas, tal como Pío Cid arranca a Mercedes de la influencia de Juanito Olivares.

En el personaje de Alarcón, nos impresiona su carácter estoico: Lázaro "sacaba a relucir las inflexibles teorías de su moral estoica, comparaba con ellas todo lo que habíamos dicho, nos demostraba que éramos reos de mil clases de delitos y pecados, y nos aconsejaba cosas tan impracticables en la sociedad profana y en nuestro modo de pensar de entonces. .."’ Pío Cid observa una actitud análoga, aunque más práctica, dado su papel de pseudo-educador. Alarcón acentúa las palabras del padre Manrique acerca del alma humana, para destacar que hay facultades más poderosas que la de la razón pura, o sea las revelaciones de la conciencia, de los sentimientos, de la inspiración, del instinto. También Ganivet ve en los autores positivistas "una plaga más temible que la langosta" (Los trabajos. .., p. 443). En Lázaro hay una ausencia completa de ideal sentimental, mientras que sus amigos viven pasiones que se desencadenan hasta el punto de llegar a constituir el elemento principal de Ia trama. Lázaro permanece incólume, y desde la cumbre de su serenidad modera la exaltación sentimental de los otros. Tanto no se puede decir de Pío Cid. Ganivet nos lo muestra bastante frío en La conquista del reino de Maya; pero en la segunda novela, Pío Cid protagoniza una historia sentimental junto a Rosita, inicia amoríos con Martina y se deja amar por la duquesa de Almadura. Estos afectos, aunque no superficiales, tampoco son fogosos, ya que en ningún momento responde Pío Cid con un amor tan fuerte como el que inspira, y permanece bastante tibio ante pasiones como la de Rosita y homenajes como los de Soledad de Almadura. El hecho de que Pío Cid haya tentado esas experiencias lo coloca considerablemente más cerca de Agustín Caballero que de Lázaro.

Sabida es la importancia que tiene en Galdós el simbolismo de los nombres propios. También Ganivet crea nombres como los de Soledad de Almadura, Juan de la Cruz, Cándido Vargas, Perfecto Fernández Vila. En esta perspectiva, tiene razón Robert Ricard $\left(B H i, 195^{8}\right.$, p. 495) en ver un paralelo entre el nombre de Pío Cid y el de Agustín Caballero, ya que "el Cid histórico, o mejor, el legendario, era el caballero por excelencia". Los dos caracteres son la interpretación particular de las cualidades de un caballero que en una escuela muy española -la de allende Ios mares- aprenden las leyes del vivir. Ganivet contagia a su

5 El escándalo, Guadalajara-Madrid, 1898 , pp. 86-87. 
personaje con este afán de colocar nombres que vayan de acuerdo con la personalidad de cada uno. Así, Pío Cid da nuevos nombres a los miembros de la familia de Martina, y prefiere llamar a una persona por un nombre inventado que sea más expresivo que el verdadero. Sabemos, además, gracias a su epistolario, que Ganivet anduvo buscando para su héroe, durante mucho tiempo, un apellido muy español, corriente sin ser vulgar.

Por supuesto, el valor simbólico de ciertos nombres es más patente en las novelas de Galdós que en las de Ganivet. Éste no pudo utilizar de lleno el método, por la sencilla razón de que sus caracteres son menos acentuados que los de Galdós; los personajes de las novelas galdosianas tienen a menudo una singularidad que linda con la locura. Ganivet siente mucha admiración por los personajes desequilibrados, y, pensando justamente en la obra de Galdós, llega a decir que "el loco es el gran asunto del arte" (Carta v, p. 858). Esta afirmación lo sitúa muy cerca del Federico Viera de Realidad: el que piensa o hace algo extraordinario recibe el título de loco porque una sociedad innoble y sin principios no comprende nada que sea grande. El genio poético y la inspiración pasan a ser locuras; todos los grandes hombres son locos. ¿Qué quiere el mundo? Establecer un nivel de vulgaridad que nadie debe sobrepasar?

Estos elementos precisos de la obra de Galdós no parecen ser los úni$\cos$ que influyeron en Ganivet. En Los trabajos de Pio Cid adquiere mucho relieve la burocracia, lo cual nos hace pensar en la atmósfera de Miau y de La de Bringas, en aquel Madrid que se iba convirtiendo en gran ciudad (se instalaba el gas, la moda recibía la influencia francesa, el oro cedía el lugar a los billetes de banco). Este período de evolución, que Ganivet no acentúa demasiado, es evidente en su principal personaje femenino, Martina, carácter sensual y sediendo de vida, que vibra en el ambiente de Madrid. La ciudad misma de Madrid desempeña uno de los principales papeles en Los trabajos de Pio Cid, y ello puede ser un testimonio de la importancia que la metrópoli gana en la novela española a partir de Galdós.

Vemos, pues, que varios elementos de las novelas de Ganivet se remontan a la obra de Galdós, y algunos a la de Alarcón. La sociedad galdosiana estaba más cerca de la sensibilidad de Ganivet, orientada decididamente hacia el realismo; y a pesar de que a menudo escapa de la atmósfera de Galdós, como en el caso de La conquista del reino de Maya, su perspectiva crea personajes que siguen el criterio realista del autor de Angel Guerra.

Hunter College, New York.

Juan Ventura Agudiez

Realidad, Madrid, 1916, p. 215. 